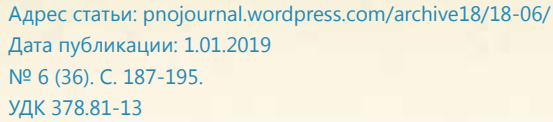

Предметом рассмотрения в настоящей статье являются возможности использования корпусных технологий в реализации проектной деятельности студентов высших учебных заведений, изучающих немецкий язык. Проектная деятельность призвана обеспечить возрастающие познавательные потребности студентов и повысить эффективность процесса обучения, ориентированного не на вкладывание знаний в обучающихся, а на самостоятельный поиск, отбор, анализ информации с использованием информационно-коммуникационных ресурсов. В качестве основных методов исследования используются теоретический анализ, обобщение и интерпретация научных данных, изучение и обобщение педагогического опыта в сфере высшего образования студентов, педагогическое проектирование, корпусная методика. Раскрываются понятия компетентностного подхода в современном образовании, проектной деятельности, проектной компетентности, лингвистического корпуса, а также основополагающие характеристики метода проектов и условия, способствующие формированию проектной культуры студентов. Рассматриваются примеры внедрения корпусных технологий в различные типы проектной деятельности на уроках немецкого языка: исследовательский, информационный, практико-ориентированный, творческий, игровой; описываются некоторые варианты конечных продуктов - результатов проектной деятельности.

Ключевые слова: корпусная лингвистика, лингвистический корпус, методика, проектная деятельность, образовательные стандарты, компетентностный подход, информационные технологии, немецкий язык, высшее учебное заведение

\title{
The Use of Linguistic Corpora in Design Activities on German Language Lessons at the University
}

The subject of investigation in this article is the possibility to use corpus-based technology in implementing the design activities in German language learning by university students. The design activities is challenged to satisfy the growing cognitive requirements in students and to improve the efficiency of educational process, oriented not on depositing knowledge into trainees, but on independent exploration, selecting, analyzing the information with the use of informational and communicative resources. Theoretical analysis, consolidation and interpretation of scientific data, investigation and consolidation of pedagogical experience in the sphere of higher education students, pedagogical designing, corpus-based methodology are used as main research methods. The notions of competency-based approach in modern education, design activities, design competence, linguistic corpus, as well as generic characteristics of design method and the conditions promoting design culture formation in students, are disclosed. The examples of corpus-based technology implementation in various types of design activities on German language lessons are investigated: research, informational, practice-oriented, creative, playing; some versions of end products - design activities results are described.

Key words: corpus-based linguistics, linguistic corpus, methodology, design activities, educational standards, competency-based approach, information technology, German language, higher educational establishment 
Только те знания прочны и ценны, которые вы добыли сами, побуждаемые собственной страстью. Всякое знание должно быть открытием, которое вы сделали сами.

\section{К. И. Чуковский}

Введение

овременное общество со стремительно развивающимися технологиями требует подготовки конкурентоспособных специалистов с определенным набором профессионально-квалификационных характеристик. Формальное овладение набором профессиональных знаний уже не удовлетворяет требованиям качества образования, поскольку в формирующейся новой системе ценностей приобретают значимость такие черты, как динамизм, умение добывать и обрабатывать информацию, ориентироваться в потоке информации, самообразование и мобильное реагирование на изменения. В связи с этим идет постоянный процесс усовершенствования подготовки кадров в учебных заведениях. Российскому образованию нужны технологии и методики обучения, которые будут способствовать формированию у учащихся исследовательских компетенций. Одной из последних реакций на вызов общества и запросы работодателей стала разработка компетентностного подхода в образовании, подразумевающего «совокупность общих принципов определения целей образования, отбора содержания образования, организации образовательного процесса и оценки образовательных результатов» [9, с. 3]. В свете данного подхода результатом образовательной деятельности является формирование ключевых компетентностей. Причем, объективно обусловленный социально-экономическими реалиями, компетентностный подход уходит корнями не в педагогические теории, а в область бизнеса и подготовки профессиональных кадров. Под компетентностью понимается «особый тип организации знаний, навыков, умений и фундаментальных способностей, которые позволяют личности быть успешной в определенном виде деятельности» [1, с. 39].

Таким образом, современные требования к подготовке профессиональных кадров включают, в первую очередь, освоение деятельности на практике, практическую реализацию полученных в учебном заведении знаний, формирование навыков коммуникации и сотрудничества, адаптацию в профессиональной среде. Немаловажная роль отводится инновационной деятельности, в процессе которой осуществляется поиск самостоятельных оригинальных решений, проявляются творчество и интеллектуальные и мотивационные возможности студентов, при- обретаются и накапливаются знания и опыт. Сформировать необходимые компетентности позволяет технология проектной деятельности, внедряемая в обучение в соответствии с современными образовательными стандартами. Проектная деятельность является неотъемлемой составляющей учебного процесса и основывается на решении какой-либо теоретической или практической задачи, результат оформляется в виде какого-либо конечного продукта, например, научного исследования, доклада, мультимедийной презентации, фильма, сайта, книги, справочника, сценария, виртуальной экскурсии, модели, разработки мероприятия и т.д.

Проектная компетентность студентов - это способность субъектов образовательного процесса применять современные технологии, проектные умения и навыки для создания интегрированных проектов, использовать организованную проектную деятельность для решения задач профессионального роста и развития [5]. В отличие от школьной проектной деятельности, студенческие проекты в большей степени ориентированы на самостоятельную работу и высокий научный уровень.

Ведение проектной деятельности немыслимо на сегодняшний день без использования информационно-коммуникационных технологий. Основная направленность документов, регламентирующих цели и задачи современного образования (Федеральный закон «Об образовании в Российской Федерации» № 273 от 29.12.2012, Федеральные государственные образовательные стандарты (выстраивание системы проектного обучения), Государственная программа Российской Федерации «Развитие образования» на 2013-2020 годы от 15 апреля 2014 г. № 295, Национальный стандарт РФ «Информационнокоммуникационные технологии в образовании» от 01.07.2008 г. ГОСТ Р 52653-2006), заключается в компьютеризации и информатизации, в создании информационной образовательной среды, в которой обучающиеся могли бы интенсивнее использовать информационно-коммуникационные технологии.

Эффективной и целесообразной является интеграция новых образовательных технологий в изучение иностранных языков. В частности, принципиально новым подходом, не нашедшим пока широкого распространения, но обладающим огромным исследовательским потенциалом в преподавании иностранных языков, является использование методов корпусной лингвистики. 
Именно корпусная лингвистика предоставляет ценный инструмент для осуществления проектной деятельности на занятиях по иностранному языку, открывая широкие пути доступа к исследованию и описанию языка, разработке справочников, словарей, учебных материалов, проведению кросс-культурных исследований и т.п.

Материалы и методы

Материалом для данного исследования послужили лингвистические корпуса как источники, предоставляющие достоверную информацию о языковых фактах и материал для дидактического использования в обучении студентов высших учебных заведений немецкому языку. Лингвистический корпус (или языковой корпус) - это «большой, представленный в электронном виде, унифицированный, структурированный, размеченный, филологически компетентный массив языковых данных, предназначенный для решения конкретных лингвистических задач» [7, с. 3]. Корпусный подход рассматривается как метод проведения исследований, решения задач при создании проектов, способствующий повышению интереса и мотивации, развития творческих способностей и самостоятельности обучающихся.

В качестве основных методов исследования в данной статье использованы теоретический анализ, обобщение и интерпретация научных данных, изучение и обобщение педагогического опыта в сфере высшего образования студентов. Также работа опирается на метод педагогического проектирования, подразумевающий создание модели организации деятельности обучающихся, описание предполагаемого продукта проектной деятельности, его планирование и основные этапы осуществления.

Результаты исследования

Проектная деятельность будущего учителя немецкого языка должна быть наполнена проблемным характером. Целесообразно воспитывать у будущих учителей умение использования научного содержания в решении профессиональных проблем. Методы проектной деятельности студентов должны быть инновационными, личностно ориентированными и включать информационные технологии.

В современных педагогических исследованиях много работ посвящается использованию проектной деятельности в обучении иностранным языкам $[4 ; 6 ; 11 ; 13 ; 18]$. Однако обойденным вниманием остается вопрос о применении корпусных технологий в обучении иностранным языкам и, в частности, в проектной деятельности. А в эпоху цифровых технологий данная методика должна занять достойное место в учебном процессе $[16 ; 19 ; 20 ; 22]$.
Целью настоящей статьи является рассмотрение возможностей организации проектной деятельности на основе лингвистических корпусов при обучении студентов немецкому языку.

В теоретических источниках выделяют в зависимости от вида деятельности, как правило, следующие типы проектов: исследовательские, информационные, прикладные (практические, практико-ориентированные), творческие и игровые (роле-игровые). По длительности проекты могут быть как долгосрочными, так и краткосрочными.

Исследовательские проекты представляют собой наиболее приемлемую категорию проектной деятельности для студенческой аудитории. В основном такого рода проекты имеют структуру научного исследования. Однако исследовательский проект может быть выполнен и в течение одного занятия. K примеру, преподаватель ставит задачу вывести путем анализа данных лингвистического корпуса какое-либо грамматическое явление, значение слова, его этимологию и развитие значения в диахронии, стилистические особенности текста и др. Исследовательский проект нацелен на развитие способностей четко формулировать задачу, осуществлять отбор релевантной информации, анализировать материал, обобщать и делать выводы.

Информационный проект строится на сборе и анализе новой информации, обобщении данных и презентации выводов. Такой тип проекта может быть направлен на изучение языковых явлений (лексических, грамматических, фонетических, стилистических), подбор примеров к изучаемому явлению, анализ, обобщение и сопоставление с известными фактами с последующим подтверждением или опровержением существующих положений, формулированием аргументированных выводов. Результаты информационного проекта представляются аудитории, к примеру, в виде доклада на конференции, презентации, научной публикации и т.п.

Прикладной проект нацелен на практическое применение полученных и освоение новых компетенций в процессе накопления практического опыта, разработку новых путей решения поставленной задачи. В качестве конкретного продукта прикладного проекта, реализуемого на основе методики корпусной лингвистики, можно предложить составление словарей, справочников, учебных пособий, аналитических и методических разработок, создание упражнений для изучающих немецкий язык, обучающих сайтов. Результат должен быть ориентирован на потребности и интересы участников проекта. Данные лингвистических корпусов предоставляют хорошую доказательную базу, которую студенты выстраивают путем эмпирических исследований, анализа, использования статистических показателей.

Творческий проект, в отличие от описанных выше проектов, имеет менее жесткую структу- 
ру, в основном здесь все зависит от интересов и креативности исполнителей. На начальном этапе проекта может быть оговорен конечный продукт, но сам процесс реализации проекта проходит в относительно свободной форме. Это может быть издание газеты, видеофильма, игрового обучающего сайта, какого-либо подкорпуса текстов (параллельного, мультимедийного, диалектного, обучающего и др.). Интересным проектом представляется разработка методик и приемов мнемотехники с опорой на рифмы, в поиске которых также лингвистический корпус может оказать неоценимую помощь.

Роле-игровой проект, как и творческий, не предполагает четкой структуры и планирования. Участники примеряют на себя определенные роли, воплощая характеры литературных персонажей, имитируя социальные или деловые отношения и т.д. В процессе изучения иностранного языка необходимо создать условия для мотивирования обучающихся и поддержания их интереса к предмету. Как показывает практика, игровые элементы в обучении с большим энтузиазмом воспринимаются обучающимися любой возрастной группы, в том числе и студенческой аудиторией. В роле-игровых проектах создаются реальные ситуации, насыщенные учебной деятельностью. Языковые корпусы содержат не только письменные тексты, но и аудио-и видеофрагменты, естественные диалоги, записанные в различных коммуникативных ситуациях (собеседование при устройстве на работу, знакомство, разговор друзей, разговор на улице, как пройти и т.д.). Студенты, обращаясь к мультимедийным корпусам, могут исследовать коммуникативные акты, последовательности реплик, их смены и сами разыгрывать ситуации. В такой ситуации можно эмпирическим путем выявить, каким образом вербальные средства взаимосвязаны в коммуникации с невербальными (мимика, жесты), которые могут отличаться в разных культурах. Приобретенные навыки студенты, получающие квалификацию учителя иностранных языков, могут использовать в дальнейшей педагогической деятельности для оптимизации учебного процесса в школах.

Несмотря на то, что основной упор в проектной деятельности делается на самостоятельность, роль преподавателя нельзя недооценивать. Задача преподавателя при реализации проектной деятельности - организовать совместную работу студентов, осуществлять координацию действий, консультировать и контролировать ход проекта. На разных этапах осуществления проекта могут проводиться дискуссии, «круглые столы», «мозговой штурм», анализ проделанной работы и обмен приобретенным опытом.

Проектная деятельность, связанная с работой с лингвистическими корпусами, требует и определенной организации информационного пространства образовательного учреждения, которое должно предоставить соответствующее материально-техническое и учебно-методическое оснащение (компьютеры, интернет, программное обеспечение).

Обсуждение результатов

Остановимся на некоторых примерах возможного использования лингвистических корпусов в проектной деятельности студентов.

В исследовательской деятельности это могут быть социальные, кросс-культурные, концептуальные, статистические, переводческие, диахронические исследования языка $[10,15]$. Принципиально важно, чтобы направление исследовательской работы согласовывалось с получаемой студентом специальностью, и решаемая задача была взята из жизни и представляла интерес для участников. Исследовательские проекты позволяют готовить самостоятельно и творчески мыслящих специалистов. Проводя исследования, связанные с немецким языком, студент углубляет и расширяет свои знания. Не навязанные учителем или учебником, а самостоятельно выведенные языковые факты, сформулированные теоретические представления приобретают особую значимость и усваиваются гораздо легче и запоминаются надолго.

По предметно-содержательной области особый интерес могут представлять междисциплинарные проекты, позволяющие с опорой на лингвистические данные корпусов проводить комплексные исследования социальных, культурных, литературных и других феноменов.

Рассмотрим пример подобного исследования [10]. Глобальный характер миграционных процессов в последние годы вызывает эскалацию напряжения во всех сферах: экономической, политической, культурной. Особо остро проблема беженцев коснулась Германии. Поэтому актуальным представляется изучение отношения немцев к иммигрантам, характер его изменения с течением времени. Заключения относительно этих проблем также позволяет сделать корпусная лингвистика. С опорой на статистические данные из корпусов удалось сделать выводы относительно периодов обострения проблем с беженцами в Германии (резкий взлет кривой вхождений ключевых слов к 2016 году).

В немецком языке есть целый ряд лексем, обозначающих мигрантов: Einwanderer, Migrant, Flüchtling, Immigrant, Zuzügler, Zugereister, Neubürger, Ausländer, Asylbewerber, Arbeitsmigrant, Spätaussiedler, Vertriebene, Asylsuchende, Asylbegehrende, Kinder und Jugendliche mit Migrationshintergrund, Zuwanderer, Schutzsuchende, Binnenvertriebene, Gastarbeiter (они были выявлены при анализе газетных статей в немецком корпусе DWDS). Bce лексемы представляют собой полные и стилистические или контекстуальные синонимы. Однако, 
несмотря на пейоративную коннотацию слова Flüchtling, ему до сих пор отдается предпочтение, что выявляется путем анализа частотности и сопоставления временных рамок.

Дальнейший анализ сочетаемости со словами Einwanderung и Zuwanderung выявляет преобладание негативно маркированной лексики в комбинации с первым словом. Меньше негативных ассоциаций вызывает употребление слова Zuwanderung, хотя и здесь речь идет о нелегальности, неконтролируемости въезда; но это слово больше связывают с трудовой миграцией, о чем свидетельствует такой ассоциативный ряд, как: рабочая сила, рынок труда, квалифицированные кадры. Если проследить в диахроническом аспекте употребительность этих двух терминов, то можно констатировать неуклонный рост употребительности термина Zuwanderung по отношению к Einwanderung, график частотности последнего проявляет гораздо большие колебания. Таким образом, анализируя языковые факты, можно в целом сделать выводы об отношении современного немецкого общества к мигрантам.

В качестве практико-ориентированного проекта можно предложить студентам создание разного рода словарей на базе лингвистических корпусов. Использование корпусного подхода, методов для определения лексической совместимости позволяет создавать словари экспериментального типа, которые направлены на выполнение определенных задач, в том числе словари семантически целостных единиц. Это позволит провести анализ взаимодействия слов, особенностей их сочетаемости, функционирования и частотности употребления. Имеющиеся словари синонимов, словообразований, во-первых, преследуют лишь количественную цель рассмотренных примеров, во-вторых, часто делают это хаотично, поэтому и возникает потребность в практико-ориентированном словаре нового типа, который можно будет назвать интегрированным тематическим словарем устойчивых словосочетаний по разным специализированным областям, или словарем коллокаций, который будет содержать разные типы устойчивых словосочетаний, наиболее востребованных при общении в той или иной сфере, показывать правильность их сочетаемости, управления.

Данный словарь впоследствии можно использовать в учебном процессе. Коллокации представляют жестко связанные между собой, устойчивые словосочетания, состоящие из разных частей речи, например, из глагола и существительного, прилагательного и существительного: задать вопрос / eine Frage stellen (поставить вопрос), сесть за круглый стол (круглый стол - стол переговоров, а не круглый по форме). Поскольку лексика, используемая в русском и немецком языках, при этом не совпадает, словарь поможет снять трудности у студентов в этом аспекте. Использование корпуса для составления словаря имеет большое преимущество. Быстрота, с которой формируется запрашиваемый материал, позволяет осуществлять подбор в ограниченные сроки. Это в значительной мере экономит время. Тем не менее подобного рода деятельность требует скрупулезности, сбора и обработки обширного объема материала. Поэтому словарный проект лучше осуществлять не индивидуально, а в группах.

На первом этапе студенты делятся на микрогруппы и продумывают структуру конечного продукта. Далее происходит сбор сочетаний с лексикой родного языка с использованием данных Национального корпуса русского языка (НКРЯ) [12]. Также отбор можно осуществлять из словарей коллокаций русского языка $[2,3]$, путем поиска примеров в текстах разных функциональных стилей. Используя корпусный подход, можно выявить: 1. Какие значения имеет конкретное слово? 2. Какова частотность употребления данного слова относительно других близких к нему слов? 3. Какие нелингвистические модели имеет данное слово (по отношению к регистрам, историческим периодам, диалектам и т.д.)? 4. Какие слова обычно сочетаются с данным словом? 5. Как распределены смыслы и типы использования слова? 6. Как используются и по-разному распределяются слова, кажущиеся синонимичными? [17]

Использование материала корпусов немецкого языка обеспечивает актуальность, репрезентативность и сбалансированность языкового материала, а также поисковый инструмент, который обычно дает возможность хорошей выборки в определенном корпусе.

На примере существительного Tisch (стол) можно представить, какие сочетания с данным словом могут представлять трудности при переводе с немецкого языка, проанализировать этапы, которые смогут впоследствии выполнять студенты самостоятельно. Используя корпус немецкого языка DWDS, можно выстроить двойную траекторию работы над словом при создании словаря. С одной стороны, можно начинать исследование слова Tisch с анализа его коллокатов, т.е. слов, с которыми исследуемое слово встречается наиболее часто и семантически целостно. К примеру, в русском языке со словом стол имеются устойчивые словосочетания: убирать со стола, беседа за круглым столом, бесплатный стол, во главе стола, просить за стол, шведский стол. Подобные устойчивые словосочетания русского языка могут вызвать трудность для студентов при переводе на немецкий язык с точки зрения правильности выбора лексики. И работа со словарем не всегда может дать правильный вариант.

Воспользовавшись корпусом немецкого языка DWDS [21], можно на примерах проанализировать сочетаемость немецкого существительного Tisch с различными частями речи (см. рис. 
1). Как видно из схемы, наиболее частыми его коллокатами являются слова Stuhl, rund, gedeckt, sitzen. Кроме этого, здесь же можно проследить, как существительное Tisch может сочетаться с различными словами в предложении, в каких синтаксических функциях оно выступает.

Одним из преимуществ корпусного исследования является то, что лингвистические корпусы можно использовать для демонстрации множества контекстов, в которых употребляется слово. Затем из этих контекстов, используя конкордансные словосочетания (KWIC), можно выделить разные смысловые значения, ассоциируемые с данным словом (см. рис. 2).

При этом корпус помогает проверить, насколько часто то или иное словосочетание име-

Suche im DWDS-Wortprofil

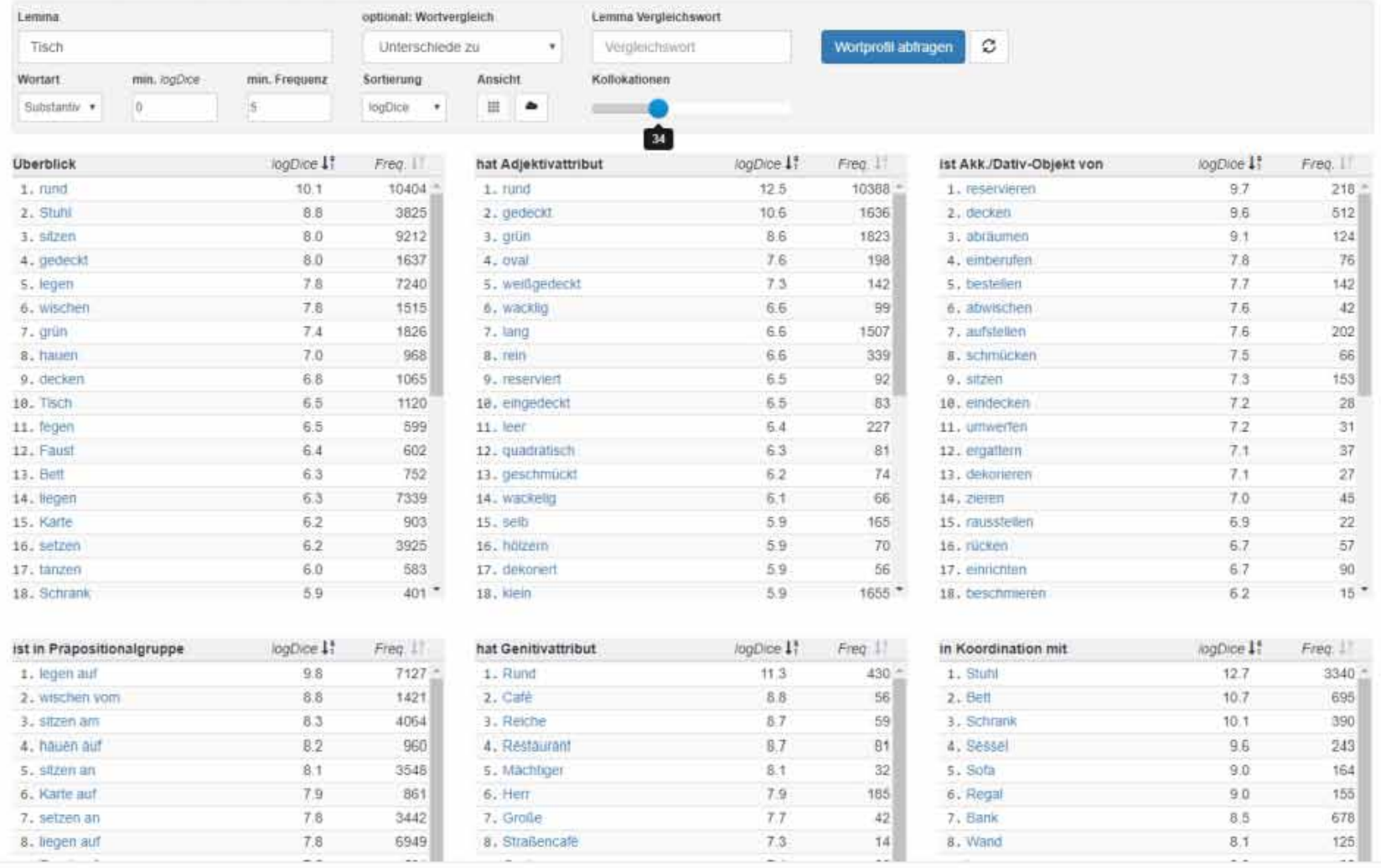

Рис. 1 Сочетания со словом "Tisch". Поиск в DWDS

\section{D $\mathbf{W}|\mathbf{D}| \mathbf{S}$}

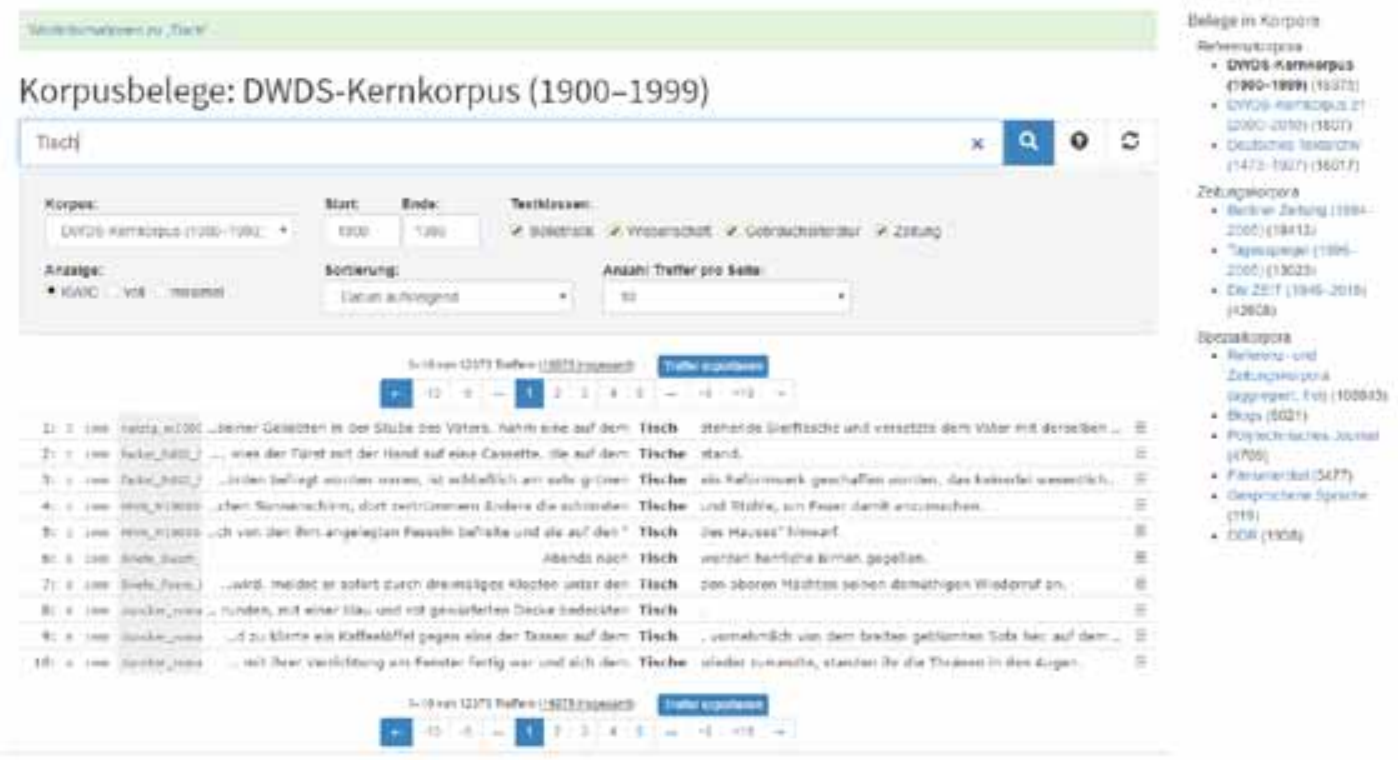

Pис. 2 "Tisch" в контексте - KWIC очетания со словом 
ет реализацию и насколько найденное значение из словаря подтверждается примерами из в аутентичном тексте. Работа подобным образом не только поможет снять трудности перевода определенных словосочетаний, но является для студентов важным совместным проектом, рассчитанным на следующие поколения, которые смогут пополнять словарь.

В качестве более масштабного проекта на основе корпусной лингвистики может быть предложено создание интерактивной онлайн-лаборатории, чтобы с помощью увлекательных и нестандартных лингвистических заданий показать, как читать и понимать текст, как функционируют слова в языке, как они связываются между собой. Целевой аудиторией сайта могут быть как студенты лингвистических направлений подготовки, которые могут самостоятельно повысить уровень владения языком, так и школьники. Во время работы над контентом разрабатываемого ресурса происходит активизация познавательной деятельности обучающихся, формирование мотивации к обучению, также это дает широкие возможности для самостоятельной работы обучающихся и контроля со стороны преподавателей. Создание сайта-лаборатории можно рассматривать как вклад в формирование ИКТкомпетенций обучающихся, а также развитие дистанционных технологий в обучении, что позволяет к тому же овладевать иностранным языком и обучающимся с ограниченными возможностями здоровья.

Работа с сайтом-лабораторией даст возможность обучающимся более осознанно овладевать языковым материалом, будет способствовать лучшему запоминанию и усвоению материала, экономии времени на обучение, благодаря наглядности, качественно отобранному аутентичному материалу, удобной навигации сайта. Сайт может послужить отличной платформой для профориентационной работы со школьниками, проведения олимпиад, конкурсов, конференций. Несомненно, такая работа сопряжена с проявлением творческого потенциала студентов, требует работы в коллективе, будет интересна и познавательна для каждого. Наполнение контента может происходить постоянно, поэтому внутри данного большого проекта может быть реализован целый ряд отдельных проектов, что предоставит широкое поле деятельности для обучающихся и для преподавателей.

Заключение

Использование данных лингвистических корпусов при осуществлении проектной деятельности в высшем учебном заведении способствует значительной оптимизации процесса обучения и овладения ключевыми компетенциями. Данный метод является актуальным, полезным и будет интересен студентам. Особую ценность проектов, основанных на корпусных методиках, составляет прагматическая направленность на результат и возможность применения результата в практической деятельности. Работа с лингвистическим корпусом может стимулировать творческий потенциал обучающихся, активизировать познавательный процесс, развивать методику сотрудничества.

На базе лингвистического корпуса можно создать множество заданий проблемного характера для стимулирования исследовательской работы обучающихся. Корпусная методика не ограничивается анализом чисто языковых фактов, а предполагает также широкий спектр междисциплинарных проектов: на основе лингвистических данных с заданными параметрами (тематическими, хронологическими, гендерными, количественными и др.) можно проводить критический обзор социальных, политических, культурных проблем. Компетенции обучающихся в разных областях можно органично интегрировать в решение одной проблемы.

Передовые технологии в опыте проектной деятельности на уроках иностранного языка должны стать неотъемлемым звеном в учебной и исследовательской деятельности обучающихся высших учебных заведений как новое направление, соответствующее современным стандартам образования и потребностям общества. А внедрение корпусных методик в проектную деятельность будет способствовать развитию мотивации к обучению и творчеству, навыков проведения исследований, способностей анализировать и делать выводы, самостоятельности и умения работать в команде, формировать профессиональное мировоззрение и определенную культуру.

ЛИТЕРАТУРА

1. Байденко В.И. Стандарты в непрерывном образовании: концептуальные, теоретические и методологические проблемы. М.: Исследовательский центр проблем качества подготовки специалистов, 1999. 296 с.

2. Бирюк О.Л., Гусев В.Ю., Калинина Е.Ю. Словарь глагольной сочетаемости непредметных имен русского языка // Национальный корпус русского языка. М., 2008. URL: http://www.ruscorpora.ru/ dict.ruslang.ru/abstr_noun. php? (дата обращения: 19.09.2018)

3. Борисова Е.Г. Слово в тексте. Словарь коллокаций (устойчивых словосочетаний) русского языка с англорусским словарем ключевых слов. М.: Филология, 1995. 148 с.

4. Борисова Е.М. Проект на уроках немецкого языка // Иностранные языки в школе. 1998. № 2. С. $27-31$.

5. Бреднева Н.А. Формирование проектной компетентности студентов в образовательном процессе вуза // 
Филологические науки. Вопросы теории и практики. Тамбов: Грамота, 2017. № 5 (71). Ч. 2. С. $166-169$.

6. Демченко А.И., Алипулатова Н.С. Проектная деятельность в обучении иностранному языку // Известия Дагестанского государственного педагогического университета. Естественные и точные науки. Махачкала: Дагестанский государственный педагогический университет, 2013. № 2. С. 106.

7. Захаров В. П. Корпусная лингвистика. Учебно-метод. Пособие. СПб.: Санкт-Петербургский государственный университет, 2005. 48 с.

8. Кашлева Н.В., Дмитриева Ж.В., Игнаткина Т.В. Школьная проектная лаборатория. Волгоград: Учитель, 2009. 154 c.

9. Лебедев О.Е. Компетентностный подход в образовании // Школьные технологии. 2004. №5. С. 3-12.

10. Морозов Е.А., Уразаева Н.Р. Мигранты и немецкое общество на современном этапе: вектор перемен // Социодинамика. 2017. № 11. C.45-55. DOI: 10.25136/2409-7144.2017.11.23282. URL: http://e-notabene.ru/pr/ article_23282.html. (дата обращения: 05.10.2018).

11. Муталапова А.Х. Проектная деятельность как способ социализации студентов на занятиях по иностранному языку в вузе // Актуальные проблемы гуманитарных и естественных наук. 2016. № 12-4. С. 62-65.

12. Национальный корпус русского языка. URL: http://www.ruscorpora.ru (дата обращения: 05.10.2018).

13. Петухова А.А. Метод проектов на уроках иностранного языка // Научно-методический электронный журнал «Концепт». 2017. Т. 33. С. 75-80. URL: http://e-koncept.ru/2017/771134.htm (дата обращения: 05.10.2018).

14. Полат Е.С. Метод проектов на уроках иностранного языка // Иностранные языки в школе. 2000. № 3. С. 3-9.

15. Уразаева Н.Р., Морозов Е.А. Концептуализация образа России в немецких СМИ: перемены к лучшему? // Мировая политика. 2017. № 3. C.141-154. DOI: 10.25136/2409-8671.2017.3.24004. URL: http://e-notabene.ru/ wi/article_24004.html (дата обращения: 05.10.2018).

16. Уразаева Н.Р., Морозов Е.А. Корпусная лингвистика при обучении немецкому языку: практические основы и инструменты // Современное образование. 2018. № 3. C.71-79. DOI: 10.25136/2409-8736.2018.3.27120. URL: http://e-notabene.ru/pp/article_27120.html (дата обращения: 05.10.2018).

17. Biber D., Conrad S., Reppen R. Corpus Linguistics. Investigating language structure and use. Cambridge University Press, 1998. 300 p.

18. Bolsunovskaya L., Phillips Ch., Korotchenko T., Matveenko I., Ulyanova O. Project-based Method in Teaching Foreign Language for Specific Purposes // Procedia - Social and Behavioral Sciences, Vol., 215. Tomsk, 2015, pp. 176-180.

19. Cheng W., Warren M., XuXun-feng. The language learner as language researcher: putting corpus linguistics on the timetable // System. Volume 31, Issue 2, June 2003, Pp. 173-186.

20. Craig E. The contribution of descriptive corpus linguistics to English language teaching // Linguistics and Education. Volume 22, Issue 3, September 2011, Pages 290-293.

21. DWDS - Wortauskunftssystem zur deutschen Sprache in Geschichte und Gegenwart [Электронный ресурс]. URL: https://www.dwds.de (дата обращения: 03.08.2018).

22. Gilquin G. Corpus-based Research in Applied Linguistics. Studies in Honor of Doug Biber // Journal of English for Academic Purposes. Volume 22. June 2016. pp. 196-198.

REFERENCES

1. Baidenko V.I. Standards in continuing education: conceptual, theoretical and methodological problems. Moscow, Research Center for the problems of the quality of training, 1999. 296 p. (in Russian)

2. Biryuk, O.L., Gusev, V.Yu., Kalinina, E.Yu. Dictionary of the verbal compatibility of non-object names of the Russian language // National Corpus of the Russian language. Moscow, 2008. Available at: http://www.ruscorpora.ru/ dict. ruslang.ru/abstr_noun.php? (accessed 19 September 2018) (in Russian)

3. Borisova E.G. The word in the text. Dictionary of collocations (stable phrases) of the Russian language with the English-Russian dictionary of keywords. Moscow, Philology Publ., 1995. 148 p. (in Russian)

4. Borisova E.M. The project at the lessons of the German language. Foreign languages at school. 1998. no. 2. pp. 27-31. (in Russian)

5. Bredneva N.A. Formation of project competence of students in the educational process of the university. Philological sciences. Questions of theory and practice. Tambov: Diploma, 2017. № 5 (71). Part 2. P. 166-169. (in Russian)

6. Demchenko A.I., Alipulatova N.S. Project activities in teaching a foreign language // Proceedings of the Dagestan State Pedagogical University. Natural and exact sciences. Makhachkala: Dagestan State Pedagogical University, 2013. no. 2. pp. 106. (in Russian)

7. Zakharov V. P. Corpus linguistics. Learning method. Saint Petersburg, SPSU Publ., 2005. 48 p. (in Russ.)

8. Kashleva N.V., Dmitrieva Z.V., Ignatkina T.V. School design laboratory. Volgograd, Teacher Publ., 2009. 154 p. (in Russ.)

9. Lebedev O.E. Competence approach in education. School technologies. 2004. no. 5. pp. 3-12. (in Russian)

10. Morozov E.A., Urazaeva N.R. Migrants and the German society at the present stage: the vector of change. Sociodynamics. 2017. no. 11. pp. 45-55. doi: 10.25136/2409-7144.2017.11.23282. Available at: http://e-notabene. ru/pr/article_23282.html. (accessed 19 September 2018). (in Russian)

11. Mutalapova A.Kh. Project activity as a way of socializing students in foreign language classes at a university. Actual problems of the humanities and natural sciences. 2016. no. 12-4. pp. 62-65. (in Russian)

12. National Corps of the Russian language. Available at: http://www.ruscorpora.ru (accessed 19 September 2018). (in Russian)

13. Petukhova A.A. Method of projects in foreign language lessons. Concept. 2017. Vol. 33. pp. 75-80. Available at: http://e-koncept.ru/2017/771134.htm (accessed 19 September 2018). (in Russian)

14. Polat E.S. Method projects in foreign language lessons. Foreign languages at school. 2000. no. 3. pp. 3-9. (in Russ.) 
15. Urazaeva N.R., Morozov E.A. Conceptualization of the image of Russia in the German media: change for the better? Global politics. 2017. no. 3. pp. 141-154. doi: 10.25136 / 2409-8671.2017.3.24004. Available at: http://e-notabene. ru/wi/article_24004.html (accessed 19 September 2018). (in Russian)

16. Urazaeva N.R., Morozov E.A. Corpus linguistics in teaching German: practical basics and tools. Modern Education. 2018. no. 3. pp. 71-79. doi: 10.25136 / 2409-8736.2018.3.27120. Available at: http://e-notabene.ru/pp/ article_27120.html (accessed 19 September 2018). (in Russian)

17. Biber D., Conrad S., Reppen R. Corpus Linguistics. Investigating language structure and use. Cambridge University Press, 1998. 300 p.

18. Bolsunovskaya L., Phillips Ch., Korotchenko T., Matveenko I., Ulyanova O. Project-based Method in Teaching Foreign Language for Specific Purposes. Procedia - Social and Behavioral Sciences, Vol., 215. Tomsk, 2015, pp. 176-180.

19. Cheng W., Warren M., XuXun-feng. The language learner as language researcher: putting corpus linguistics on the timetable. System. Volume 31, Issue 2, June 2003, Pp. 173-186.

20. Craig E. The contribution of descriptive corpus linguistics to English language teaching. 2001. Linguistics and Education. Volume 22, Issue 3, September, pp. 290-293.

21. DWDS - Wortauskunftssystem zur deutschen Sprache in Geschichte und Gegenwart [Электронный ресурс]. Available at: https://www.dwds.de (accessed 19 September 2018).

22. Gilquin G. Corpus-based Research in Applied Linguistics. Studies in Honor of Doug Biber. Journal of English for Academic Purposes. 2016, Vol. 22. June, pp. 196-198.

\section{Информация об авторах \\ Морозов Евгений Александрович (Россия, Магнитогорск)}

Доцент, кандидат филологических наук Магнитогорский государственный технический университет им. Г.И. Носова

E-mail: buddenbroki@mail.ru

\section{Уразаева Наиля Радифовна}

(Россия, Магнитогорск)

Доцент, кандидат филологических наук Магнитогорский государственный технический университет им. Г.И. Носова

E-mail: nailja-urasaewa@yandex.ru
Information about the authors Evgeny A. Morozov

(Russia, Magnitogorsk) Associate Professor, $\mathrm{PhD}$ in Philological Sciences Nosov Magnitogorsk State Technical University E-mail: buddenbroki@mail.ru

Nailya R. Urazaeva

(Russia, Magnitogorsk)

Associate Professor,

$\mathrm{PhD}$ in Philological Sciences

Nosov Magnitogorsk State Technical University E-mail: nailja-urasaewa@yandex.ru

\section{Ссылка для цитированиягост}

Морозов Е. А., Уразаева Н. Р. Использование лингвистических корпусов в проектной деятельности на занятиях по немецкому языку в высшем учебном заведении // Перспективы науки и образования. 2018. № 6 (36). С. 187-195. doi: 10.32744/ pse.2018.6.21

\section{For Reference ${ }^{\mathrm{APA}}$}

Morozov, E. A., \& Urazayeva, N. R. (2018). The use of linguistic corpora in design activities on German language lessons at the university. Perspektivy nauki $i$ obrazovania - Perspectives of Science and Education, 36 (6), 187-195. doi: 10.32744/pse.2018.6.21 